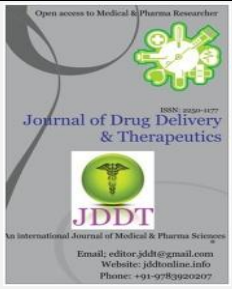

\title{
FORMULATION AND EVALUATION OF ONION HAIR NOURISHING SHAMPOO
}

\author{
Patel Naziya Rafik, Mohite Swapnali Arun, Shaha Rutuja Rajendra \\ Adarsh College of Pharmacy Vita, Maharashtra, India 415311
}

\begin{abstract}
Shampoo is the most basic cosmetic used for hair, containing antimicrobial agent and other ingredient commonly used. The main function of shampoo is to clean the hair properly and reduce the dandruff. In present work we have formulated onion and eucalyptus oil herbal shampoo for the dry hair. The most common problem in people is related to the dry. Hence research was carried out on dry hair remedy. The formulation was evaluated for various parameters. The formulation of F2 batch shows best result of evaluation parameters as compare to the F1 and F3. The Formulation F2 showed good efficacy. The optimized batch formulation of F2 showed good microbial activity. The advantage of the this herbal shampoo is better nutrient and nourishment to hair follicles and to promote the hair growth and to overcome on dryness problem. The onion used in this formulation as it promotes hair growth and the eucalyptus oil used for the antimicrobial activity for the preparation.
\end{abstract}

Keyword: onion, eucalyptus oil, herbal shampoo, nourishing property

Article Info: Received 10 June, 2018; Review Completed 13 July 2018; Accepted 14 July 2018; Available online 17 July 2018

Cite this article as:

Patel NR, Mohite SA, Shaha RR, Formulation and evaluation of onion hair nourishing shampoo, Journal of Drug Delivery and Therapeutics. 2018; 8(4):335-337 DOI: http://dx.doi.org/10.22270/jddt.v8i4.1810

*Address for Correspondence:

Patel Naziya Rafikm Adarsh College of Pharmacy Vita, Maharashtra, India 415311

\section{INTRODUCTION}

Herbal shampoo is a cosmetic preparation which uses herbs from plants and it is meant for washing of hair and scalp just like a regular shampoo. It is an alternative to the synthetic shampoo available in market. Herbalists today, believe in helping people build their good health with the help of natural sources 1,2

The onion (Allium cepa L, from Latin cepa "onion"), also known as the bulb onion or common onion, is a vegetable that is the most widely cultivated species of the genus Allium. Its close relatives include the garlic, shallot, leek, chive] and Chinese onion Allium cepa family Liliaceae "has been reported to possess antimicrobial, antibacterial, better nourishment, nutrients and also used as hair scalper hair loss ${ }^{3,4}$.

In formulated shampoo eucalyptus oil is used as it shows antifungal activity. The eucalyptus oil is the collected from the market .In the formulation various ingredients are used coconut oil (moistening agent), castor oil (thinning agent ), potassium hydroxide (disinfectant), glycerol (surfactant ), borax (cleansing agent), acacia (emulsifying agent ), allium cepa extract (scalp reduce agent) eucalyptus oil (antifungal agent ) ,sodium bicarbonate ( cleansers), lemon juice ( antidandruff agent ), methyl paraben ( preservative ), perfume (fragrance), distilled water (aqoues medium). In this formulation we checked the antimicrobial assay by the sabouraud agar or sabouraud dextrose agar or SDA. The acidic pH 5.6 of sabouraud agar inhibits bacterial growth.

\section{MATERIALS AND METHOD}

Onion was procured of good quality from local market. All the other ingredients used were of analytical grade.

The Allium cepa is extracted by the following method.

First $100 \mathrm{gms}$ of freshly bulbs of allium cepa were cutted in small pieces. These pieces take into the mixer apparatus crush the content of allium cepa then collect 
the alliun cepa. This extract is passed through the muslin cloth to take the pure extract in filtrate. This extract is used for the formulation $5,6,7$.The eucalyptus oil is collected from the marketed eucalyptus oil is used for formulation Three different formulations F1, F2, F3 were prepared. '”

Table No 1: Composition of shampoo formulation: (20) $\mathrm{ml}^{\text {” }}$

\begin{tabular}{|c|l|l|l|l|l|}
\hline Sr.No & \multicolumn{1}{|c|}{ Ingredients } & \multicolumn{1}{|c|}{ Importance } & \multicolumn{1}{|c|}{$\mathrm{F}$ 2 } & \multicolumn{1}{|c|}{$\mathrm{F} 3$} \\
\hline 1. & Coconut oil & Moistening agent & $3.6 \mathrm{ml}$ & $3.6 \mathrm{ml}$ & $3.6 \mathrm{ml}$ \\
\hline 2. & Castor oil & Thinning agent & $0.8 \mathrm{ml}$ & $0.8 \mathrm{ml}$ & $0.8 \mathrm{ml}$ \\
\hline 3. & Potassium hydroxide & Disinfectant & $1.06 \mathrm{gm}$ & $1.06 \mathrm{gm}$ & $1.06 \mathrm{gm}$ \\
\hline 4. & Glycerol & Surfactant & $0.8 \mathrm{ml}$ & $0.8 \mathrm{ml}$ & $0.8 \mathrm{ml}$ \\
\hline 5. & Borax & Cleansing agent & $0.04 \mathrm{gm}$ & $0.04 \mathrm{gm}$ & $0.04 \mathrm{gm}$ \\
\hline 6. & Acacia & Emulsifying agent & $0.04 \mathrm{gm}$ & $0.04 \mathrm{gm}$ & $0.04 \mathrm{gm}$ \\
\hline 7. & Allium cepa extract & Scalp reduce agent & $1 \mathrm{ml}$ & $2 \mathrm{ml}$ & $3 \mathrm{ml}$ \\
\hline 8. & Eucalyptus oil & Antimicrobial agent & $1 \mathrm{ml}$ & $2 \mathrm{ml}$ & $3 \mathrm{ml}$ \\
\hline 9. & Sodium bicarbonate & Cleanser & $0.12 \mathrm{gm}$ & $0.12 \mathrm{gm}$ & $0.12 \mathrm{gm}$ \\
\hline 10. & Lemon juice & Antidandruff agent & $1 \mathrm{ml}$ & $1 \mathrm{ml}$ & $1 \mathrm{ml}$ \\
\hline 11. & Methyl paraben & Preservative & $0.06 \mathrm{gm}$ & $0.06 \mathrm{gm}$ & $0.06 \mathrm{gm}$ \\
\hline 12. & Perfume & Fragrance & q.s. & q.s. & q.s. \\
\hline 13. & Distilled water & Aqoues medium & $20 \mathrm{ml}$ & $20 \mathrm{ml}$ & $20 \mathrm{ml}$ \\
\hline
\end{tabular}

\section{Formulation of herbal shampoo:}

Coconut oil and castor oil were saponified with potassium hydroxide using reflux condenser. After complete saponification, glycerin was incorporated with stirring followed by mixing of onion and eucalyptus oil. Then add the ethyl alcohol,methyl paraben used as preservative and lemon juice used for masking smell of formulation then add the perfume and water to gives the formulation will be prepared ${ }^{7}$.

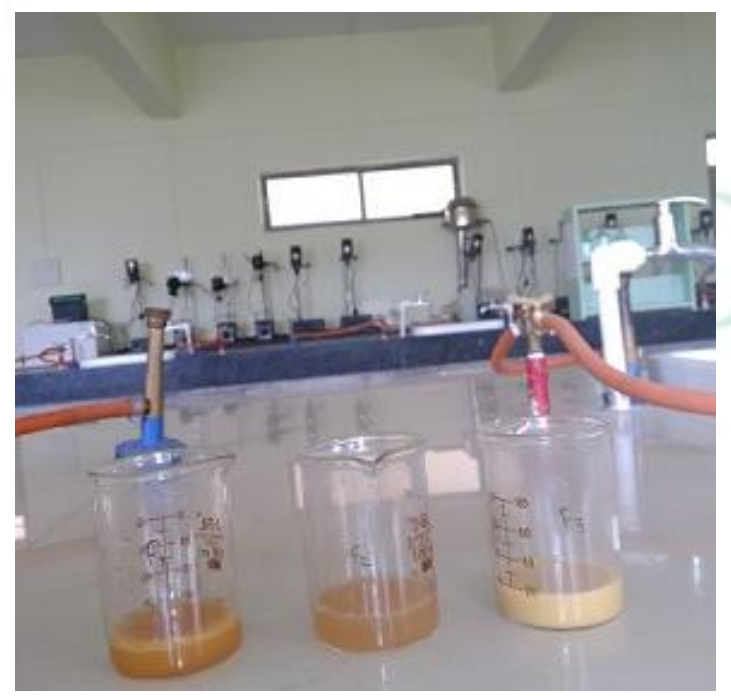

Figure 1: formulation of herbal shampoo

\section{Evaluation test for herbal shampoo:}

1. pH: The prepared formulation was checked by using $\mathrm{pH}$ paper .All the prepared formulation of 3 batches were check for their $\mathrm{pH}$ range ${ }^{8}$.

2. Physical appearance- As any other cosmetic products, the attractiveness of shampoos for consumers tends to be judged visually thus having good physical appearance is important. Hence formulated shampoo was checked for physical appearance.
3. Viscosity was determined by using the Ostwald viscometer (Borosil Pvt.Ltd) ${ }^{7}$.

4. Ease of Rinsing The time taken to remove the detergent was performed by applying $5 \mathrm{ml}$ of the shampoo and time taken for complete removal of frothing from wash water was determined.

5. Foam formation (shake test): take the shampoo in bottle and shake the bottle to foam will be produced

6. Surface tension: The surface tension is carried out by the Ostwald stalagmometer. Mount the stalagmometer in a vertical position on any suitable stand to avoid unnatural of drop. Fill the preparation in dry stalagmometer up to a level higher than mark A and count the total number of drops formed as the formulation meniscus travel from mark $\mathrm{A}$ to a mark B.Repeat the step for F2 and F3.

7. Skin irritation test: Apply the solution of prepared herbal shampoo on skin and kept for $5 \mathrm{~min}$ and observed for redness of skin and irritation ${ }^{7}$

8. Stability study ${ }^{8}$ : The stability study was carried out of the prepared herbal shampoo at standard temperature of 25-30

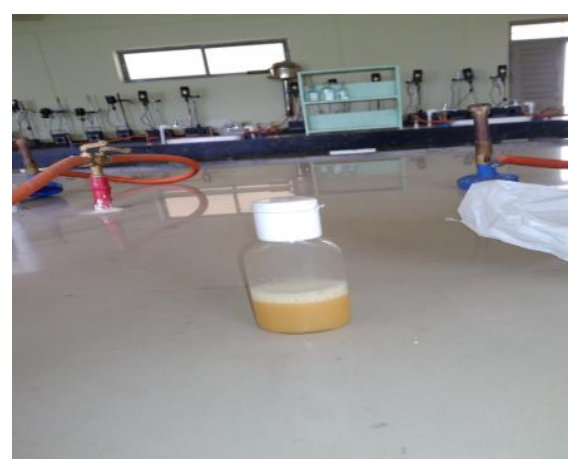

Figure 2: Formulated herbal shampoo. 


\section{RESULT}

Table 2: Evaluation of formulation of herbal shampoo for physical appearance, $\mathrm{pH}$, surface tension and viscosity

\begin{tabular}{|l|l|l|l|l|l|}
\hline $\begin{array}{l}\text { Formulation } \\
\text { code }\end{array}$ & Physical appearance & $\begin{array}{l}\text { Foaming } \\
\text { ability }\end{array}$ & pH & $\begin{array}{l}\text { Surface tension } \\
\text { (dyne/cm) }\end{array}$ & $\begin{array}{l}\text { Viscosity } \\
\text { (cp) }\end{array}$ \\
\hline F1 & Clear, no characteristics smell & Good & 14 & 25.73 & 4.13 \\
\hline F2 & Clear, no characteristics smell & Good & 13 & 19.6 & 10.88 \\
\hline F3 & Clear, no characteristics smell & Good & 10 & 29.20 & 11.89 \\
\hline
\end{tabular}

Ease of rinsing: The formulation was easy to rinse .Optimized batch formulation was rinsed out in 3 to 4 minutes easily

Skin irritation: No skin irritation was observed

Stability study: formulation remained stable.

\section{REFERENCES}

1. Shivanand P, Nilam M, Viral D. Herbs play an important role in the field of cosmetics.Int J Pharm Tech Res 2010; 2:632-9.

2. Arora P, Nanda A, Karan M. Shampoos based on synthetic ingredients vis-a-vis shampoos based on herbal ingredients: A review. Int J Pharma Sci Rev Res.2011; 7:41-6.

3. Allium cepa 1-the plan “' list "the plantlist org." publication details; sp.pl, 2013; 300: 1753.

4. ABC "All about onion" national onion association retrieved 2013-03-24.

5. https://en.m.wikipedia.org/wiki/Onion

\section{CONCLUSION}

The main aim was to formulated hair nourishing shampoo, will improve and strengthen the hair by proper nourishment and other problems like dryness and dandruf. It was concluded that formulated shampoo of F2 batch is optimized having good hair nourishing property.

6. https://en.m.wikipedia.org/wiki/Eucalyptus oil

7. Chouhan A., Jaiswal S., Malviya J., Dubey R., Barman S. Formulation, development and evaluation of herbal powder shampoo. Journal of Drug Delivery and Therapeutics, 2017; 7(7):192-193. doi:10.22270/jddt.v7i7.1632

8. Haihaywanshi M., Gouri T., Gupta A., Jain, S. Arnica hydrogel: an oil replacement for hair loss treatment .Journal of Drug Delivery and Therapeutics, 2017; 7(7):23-25. doi:10.22270/jddt.v7i7.1575 